\title{
Acquisition of carbapenemase-producing Enterobacteriaceae by healthy travellers to India, France, February 2012 to March 2013
}

E Ruppé (etienne.ruppe@gmail.com) ${ }^{1,2,3}$, L Armand-Lefèvre ${ }^{1,2}$, C Estellat ${ }^{4,5}$, A El-Mniai ${ }^{1}$, Y Boussadia ${ }^{4,5}$, P H Consigny ${ }^{6}$, P M Girard7, D Vittecoq $^{8}$, O Bouchaud 9 , G Pialoux ${ }^{10}$, M Esposito-Farèse B,5, $^{4,5}$ Coignard $^{11}$, J C Lucet $^{2,3,12}$, A Andremont ${ }^{1,2,3}$, S Matheron ${ }^{3,13}$

1. AP-HP, Hôpital Bichat, Laboratoire de Bactériologie, Paris, France

2. INSERM, IAME, UMR 1137, F-75018 Paris, France

3. Univ Paris Diderot, IAME, UMR 1137, Sorbonne Paris Cité, Paris, France

4. AP-HP, Hôpital Bichat, Département d’Epidémiologie et Recherche Clinique, URC Paris-Nord, Paris, France

5. INSERM, CIC 1425-EC, Paris, France

6. Institut Pasteur, Centre Médical, Centre d’Infectiologie Necker-Pasteur, Paris, France

7. AP-HP, Hôpital Saint-Antoine, Maladies Infectieuses et tropicales, Paris, France

8. AP-HP, Hôpital de Bicêtre, Maladies Infectieuses et Tropicales, Le Kremlin-Bicêtre, France

9. AP-HP, Hôpital Avicenne, Maladies Infectieuses et Tropicales, Bobigny, France

10. AP-HP, Hôpital Tenon, Maladies Infectieuses et Tropicales, Paris, France

11. Institut de Veille Sanitaire, Saint Maurice, France

12. AP-HP, Hôpital Bichat, Unité d'Hygiène et de Lutte contre les Infections Nosocomiales, Paris, France

13. AP-HP, Hôpital Bichat, Maladies Infectieuses et Tropicales, Paris, France

Citation style for this article:

Ruppé E, Armand-Lefèvre L, Estellat C, El-Mniai A, Boussadia Y, Consigny PH, Girard PM, Vittecoq D, Bouchaud O, Pialoux G, Esposito-Farèse M, Coignard B, Lucet JC, Andremont A, Matheron S. Acquisition of carbapenemase-producing Enterobacteriaceae by healthy travellers to India, France, February 2012 to March 2013. Euro Surveill. 2014;19(14):pii=20768. Available online: http://www.eurosurveillance.org/ViewArticle.aspx?Articleld=20768

Healthy travellers to countries where carbapenemasesproducing Enterobacteriaceae (CPE) are endemic might be at risk for their acquisition, even without contact with the local healthcare system. Here, we report the acquisition of CPE (two OXA-181, one New Delhi metallo-beta-lactamase 1 (NDM-1)) in three healthy travellers returning from India. The duration of CPE intestinal carriage was less than one month. The results indicate that healthy travellers recently returning from India might be considered as at risk for CPE carriage.

We report the acquisition of carbapenemases-producing Enterobacteriaceae (CPE) in three healthy French travellers returning from India, who declared no contact with any local healthcare centres during their journey in this country.

\section{Healthy travellers carrying carbapenemase-} producing Enterobacteriaceae

As part of the VOYAG-R study (ClinicalTrials.gov Identifier: NCTo1526187), volunteers who had planned to travel to intertropical areas for a three-day to threemonth trip were recruited in six centres for travel vaccinations in the Paris area, from February 2012 to March 2013. In total, 574 travellers (222 men and 352 women) were included, who visited 72 intertropical countries located in the Americas ( $n=183$ travellers), Africa $(n=195)$ or in the Middle East and south-east Asia $(n=196)$. This included 57 travellers who visited India. If travelling in groups, only one self-designated volunteer was solicited. Included travellers were those with a negative stool sample for multidrug-resistant Enterobacteriaceae (MRE) during the week preceding departure and those who provided a stool sample within a week after their return. Each sample was accompanied with a self-completed questionnaire. Before departure the traveller informed on the dates of departure and return, the visited country, the number of accompanying travellers, the malaria prophylaxis, and the type and purpose of the travel. After return, the traveller reported on the occurrence of digestive disorders during the travel, the intake of antibiotics, any contact with the healthcare system at travel destination and the compliance with malaria prophylaxis. During the follow-up the traveller informed of any antibiotic intake and purpose, any hospitalisation and any new travel to intertropical countries. If positive for MRE after return, the traveller was asked to provide stool samples one, two, three, six and 12 months after return, until no MRE could be detected. Among 57 travellers who had visited India, three returned to France with CPE intestinal carriage (Table).

Traveller 1 (C4-049)

A woman in her early fifties, had travelled alone as a backpacker and tourist to India for 17 days in April 2012. Upon return, she did not report any digestive disorders, any antibiotic intake or any contact with the local healthcare system during her travel. Investigation of stool samples revealed four phenotypically distinct Escherichia coli, including one that produced both a CTX-M group 1 and an OXA-181 carbapenemase. One 
Characterisation of the strains present in the stool samples of three travellers returning from India, France, February 2012March 2013

\begin{tabular}{|c|c|c|c|c|c|c|c|c|}
\hline \multirow{2}{*}{ Traveller ID } & \multirow{2}{*}{ Strain } & \multirow{2}{*}{ Species } & \multirow{2}{*}{ Beta-lactamases } & \multirow{2}{*}{ Co-resistances } & \multirow{2}{*}{ Return } & \multicolumn{3}{|c|}{ Follow-up } \\
\hline & & & & & & Month 1 & Month 2 & Month 3 \\
\hline \multirow{5}{*}{$1\left(C_{4}-049\right)$} & $\mathrm{C}_{4}-049 \mathrm{EC} 1$ & Escherichia coli & CTX-M group 1 & TE & & & & \\
\hline & $\mathrm{C}_{4}-049 \mathrm{EC2}$ & Escherichia coli & CTX-M group 1 & FQ, SXT, TE & & & & \\
\hline & $\mathrm{C}_{4}-049 \mathrm{EC} 3$ & Escherichia coli & CTX-M group 1 & $\mathrm{FQ}, \mathrm{TE}$ & & & & \\
\hline & $\mathrm{C}_{4}-049 \mathrm{EC} 4$ & Escherichia coli & OXA-181 and CTX-M group 1 & $\mathrm{FQ}$ & & & & \\
\hline & $\mathrm{C}_{4}-049 \mathrm{EC5}$ & Escherichia coli & CTX-M group 1 & GM, FQ, SXT, TE & & & & \\
\hline \multirow{2}{*}{$2\left(C_{4-417)}\right.$} & $\mathrm{C}_{4}-417 \mathrm{EC1}$ & Escherichia coli & CTX-M group 1 & $\mathrm{FQ}, \mathrm{TE}$ & & & & \\
\hline & $\mathrm{C}_{4}-417 \mathrm{EC2}$ & Escherichia coli & OXA-181 & $\mathrm{FQ}$ & & & & \\
\hline \multirow{6}{*}{$3\left(C_{4-422)}\right.$} & $\mathrm{C}_{4-422 \mathrm{EC} 1}$ & Escherichia coli & CTX-M group 1 & $\mathrm{FQ}$ & & & & \\
\hline & $\mathrm{C}_{4}-422 \mathrm{EC2}$ & Escherichia coli & CTX-M group 1 and $p A m p C$ & GM, FQ, TE & & & & \\
\hline & $\mathrm{C}_{4}-422 \mathrm{EC} 3$ & Escherichia coli & CTX-M group 1 & $\mathrm{FQ}, \mathrm{TE}$ & & & & \\
\hline & $\mathrm{C}_{4}-422 \mathrm{EC} 4$ & Escherichia coli & CTX-M group 1 & FQ, SXT, TE & & & & \\
\hline & $\mathrm{C}_{4-422 \mathrm{EC} 5}$ & Escherichia coli & pAmpC & $\mathrm{FQ}, \mathrm{SXT}, \mathrm{TE}$ & & & & \\
\hline & $\mathrm{C}_{4}-422 \mathrm{Ec} 6$ & Escherichia coli & NDM-1 and CTX-M group 1 & FQ, AN, GM, SXT, TE & & & & \\
\hline
\end{tabular}

AN: amikacin; FQ: fluoroquinolone; GM: gentamicin; ID: identifier; NDM-1: New Delhi metallo-beta-lactamase 1; pAmpC: plasmid-encoded AmpC-type cephalosporinase; SXT: trimethoprim/sulfamethoxazole; TE: tetracycline.

Black-filled cells indicate the detection of the strain in question, grey cells indicate that the strain was not detected, light grey cells indicate that no stool sample was requested (i.e. follow-up completed).

month after return, a CTX-M group 1-producing E. coli, which displayed a different resistance pattern to that of the $E$. coli recovered at return, was also detected. Two months after return, a stool sample from traveller 1 was negative for MRE.

\section{Traveller 2 (C4-417)}

A woman in her late twenties, travelled to northern India for 10 days in November 2012, with another person on a tour. She did not report any digestive disorders, any antibiotic intake or any contact with the local healthcare system during her travel. Direct cultures of stool samples collected at her return on agar media were negative, but cefotaxime enrichment broth yielded a CTX-M group 1-producing E. coli. Furthermore, the carbapenemase specific enrichment procedure used for this study yielded an OXA-181-producing E. coli. Traveller 2's stool sample, originating from one month after return, was negative for any MRE carriage.

\section{Traveller 3 (C4-422)}

A woman in her early thirties, travelled on her own to southern India for one month in January 2013, where she alternatively backpacked, participated in touristic tours and visited relatives living in India. At return, she reported having experienced digestive disorders, but she had not taken any antibiotics nor visited any healthcare centre during her journey in the country. From her stool sample at return, six phenotypically distinct $E$. coli were identified, among which one produced both CTX-M group 1 and New Delhi metallo-betalactamase 1 (NDM-1) carbapenemase. At months 1 and 2 after return, she was no longer carrying any CPE, but was still carrying one CTX-M group 1-producing $E$. coli.
A stool sample from three months after return was negative for MRE.

\section{Laboratory investigations}

\section{Detection of multidrug-resistant \\ Enterobacteriaceae}

Stool samples were stored at room temperature by the traveller until shipped by postal services to the Bacteriology laboratory of the Bichat-Claude Bernard Hospital, Paris, France, where they were cultured immediately upon reception. Approximately $10 \mathrm{mg}$ of stool was plated onto a chromID extended-spectrum beta-lactamases (ESBL) agar media (bioMérieux, Marcy-l'Etoile, France) and onto a bi-valve ESBL agar (AES Chemunex, Ivry-sur-Seine, France). In parallel, approximately $100 \mathrm{mg}$ of stool was diluted in $10 \mathrm{~mL}$ of brain heart infusion (BHI) broth, of which $1 \mathrm{~mL}$ was diluted to a BHI broth supplemented with $1.5 \mathrm{mg} / \mathrm{L}$ cefotaxime and another $1 \mathrm{~mL}$ to a $\mathrm{BHI}$ broth supplemented with $0.5 \mathrm{mg} / \mathrm{L}$ ertapenem, and incubated overnight, until $100 \mu \mathrm{L}$ of each broth were respectively plated onto a chromID ESBL agar media and a Drigalski agar plate with disks of ertapenem and imipenem, as described [1]. Plates were incubated $48 \mathrm{~h}$ at $37^{\circ} \mathrm{C}$ in aerobic conditions. All colony-forming units (CFUs) with distinct morphotypes on chromID ESBL agar media and CFUs growing within the normal inhibition radius of carbapenem disks (www.sfm-microbiologie.org) were further identified by mass spectrometry (MALDI Biotyper, Bruker, Bremen, Germany) and tested for antibiotic susceptibility by the disc diffusion method, as recommended by the French Society for Microbiology (www. sfm-microbiologie.org). 
Characterisation of the resistance mechanisms Total DNA of MRE was extracted by the EZ1 DNA Tissue Kit processed on the EZ1 instrument (Qiagen, Courtaboeuf, France). bla $a_{\mathrm{CTX}-\mathrm{M}}, b / a_{\mathrm{TEM}}, b / a_{\mathrm{SHV}}, b l a_{\mathrm{KPC}}$, bla $a_{\mathrm{VIM}}, b a_{\mathrm{IMP}}$ and $b l a_{0 \times \mathrm{OX}-48}$ were targeted with specific polymerase chain reaction (PCR) primers, as described [1-3]. bla $a_{\mathrm{NDM}}$ was targeted using the following primers: NDM-F 5'-CTGAGCACCGCATTAGCCG-3' and NDM-R 5'-CGTATGAGTGATTGCGGCG-3' Plasmidencoded AmpC-type cephalosporinases $(\mathrm{pAmpC}), \quad b l a_{\text {CIT-group }}, \quad b l a_{\text {ENT-group }}, \quad b l a_{\text {MOX }}$ and $b a_{\mathrm{Fox}}$, were targeted by the wide-range AmpCU-F 5'-GCARACSCTGTTYGAGMTDGG-3' and AmpCU-R 5'-CTCCCARCCYARYCCCTG-3' primers. Amplicons of carbapenemases-encoding genes were Sanger-sequenced with the Big Dye terminator v3 kit (Applied Biosystems, Courtaboeuf, France) for final identification.

\section{Ethical issues}

The VOYAG-R study was approved by the 'Comite de Protection des Personnes' lle de France IV (14 November 2011).

\section{Discussion and conclusion}

MRE that produce ESBL and/or plasmid-encoded AmpC-type cephalosporinases ( $\mathrm{pAmpC}$ ) have spread massively in developing countries. This phenomenon likely results from suboptimal hygiene living conditions and uncontrolled antibiotic usage [4]. Therefore, travellers may be at risk for MRE acquisition when visiting countries in which the MRE prevalence is high. In recent years, studies focusing on the acquisition of MRE during travel abroad have shown that MRE acquisition rates ranged from $14.0 \%$ to $30.5 \%$ [5-10]. Surprisingly, in those studies no CPE was isolated from healthy travellers, despite them having visited CPEendemic areas such as the Indian subcontinent. Some sporadic cases of CPE importation, with no connection with any healthcare centres, have been reported, all for travellers returning from India [11-13], but not healthy travellers.

We report the acquisition of CPE in three healthy French travellers returning from India, who declared no contact with any healthcare centres in this country. These findings are worrisome as they attest to the development of a community reservoir for CPE, at least in India.

The Indian subcontinent had already been identified as a major reservoir for antibiotic resistant bacteria, and CPE have been found in both seepage and tap water in the city of New Delhi [14]. In our study, we only found CPE in travellers returning from India. In 2010, 7.3 million citizens of the European Union travelled to India [15]. To deal with this issue, specific recommendations about the management of patients being repatriated, or patients who have recently ( 11 year) been hospitalised abroad, have been published by some European countries [16]. How these recommendations could extend to subjects who have recently travelled in CPE endemic areas may be discussed.
On a positive note, the duration of CPE carriage in the three travellers was less than one month. In former studies of acquisition of MRE by travellers, it was not clear whether the MRE carriage could be short [5] or long $[7,9]$. Despite the limited number of acquisitions of CPE, our results might suggest that, travellers immediately returning from CPE endemic areas should be considered as at risk for CPE carriage, while in the absence of antibiotic exposure, travellers at several months after their return might not pose such a risk.

Our results stress the need for a specific cultivation method for assessing the intestinal carriage of CPE when suspected, such as the one we used [1], because some CPE such as those producing OXA-48type carbapenemases (including OXA-181) do not grow on agar media formulated to detect ESBL-producing Enterobacteriaceae [1]. Some CPE might have been missed in former studies because no specific and sensitive detection of CPE was used.

In conclusion, we report here the acquisition of CPE by healthy travellers to India without contact with any local healthcare centre, while in this country. In addition to repatriated patients or patients who have recently been hospitalised abroad, travellers may be considered at occasional risk for CPE carriage.

\section{Acknowledgments}

The authors are grateful to the teams of the vaccination centres of the Avicenne, Bicètre, Bichat, Saint-Antoine and Tenon hospitals and the medical centre of Institut Pasteur. The authors would also like to thank the travellers for their participation and Sean P. Kennedy for English revision.

\section{Conflict of interest}

None declared.

Authors' contributions

$E R, L A L, C E, B C, J L M, A A$ and $S M$ designed the study, analysed the data, and reviewed the manuscript. YB, PHC, PMG, DV, OB, GP and SM included the travellers. AEM performed the microbiological analysis. MEF and CE performed the statistical analysis. ER wrote the manuscript. 
1. Ruppé E, Armand-Lefèvre L, Lolom I, El Mniai A, MullerSerieys C, Ruimy R, et al. Development of a phenotypic method for detection of fecal carriage of OXA-48-producing Enterobacteriaceae after incidental detection from clinical specimen. J Clin Microbiol. 2011;49(7):2761-2. http://dx.doi.org/10.1128/JCM.00055-11

2. Ruppé E, Hem S, Lath S, Gautier V, Ariey F, Sarthou JL, et al. CTX-M beta-lactamases in Escherichia coli from communityacquired urinary tract infections, Cambodia. Emerg Infect Dis. 2009;15(5):741-8. http://dx.doi.org/10.3201/eid1505.071299

3. Barbier F, Ruppé E, Giakkoupi P, Wildenberg L, Lucet J, Vatopoulos A, et al. Genesis of a KPC-producing Klebsiella pneumoniae after in vivo transfer from an imported Greek strain. Euro Surveill. 2010;15(1). pii: 19457.

4. Woerther PL, Burdet C, Chachaty E, Andremont A. Trends in Human Fecal Carriage of Extended-Spectrum beta-Lactamases in the Community: Toward the Globalization of CTX-M. Clin Microbiol Rev. 2013;26(4):744-58. http://dx.doi.org/10.1128/CMR.00023-13

5. Kennedy K, Collignon P. Colonisation with Escherichia coli resistant to "critically important" antibiotics: a high risk for international travellers. Eur J Clin Microbiol Infect Dis. 2010;29(12):1501-6. http://dx.doi.org/10.1007/s10096-010-1031-y

6. Ostholm-Balkhed A, Tärnberg M, Nilsson M, Nilsson LE, Hanberger $\mathrm{H}$, Hallgren A. Travel-associated faecal colonization with ESBL-producing Enterobacteriaceae: incidence and risk factors. J Antimicrob Chemother. 2013;68(9):2144-53. http://dx.doi.org/10.1093/jac/dkt167

7. Paltansing S, Vlot JA, Kraakman ME, Mesman R, Bruijning ML, Bernards AT, et al. Extended-spectrum beta-lactamaseproducing Enterobacteriaceae among travelers from the Netherlands. Emerg Infect Dis. 2013;19(8):1206-13. http://dx.doi.org/10.3201/eid1908.130257

8. Peirano G, Laupland KB, Gregson DB, Pitout JD. Colonization of returning travelers with CTX-M-producing Escherichia coli. J Travel Med. 2011;18(5):299-303. http://dx.doi.org/10.1111/j.1708-8305.2011.00548.x

9. Tängdén T, Cars O, Melhus A, Löwdin E. Foreign travel is a major risk factor for colonization with Escherichia coli producing CTX-M-type extended-spectrum beta-lactamases: a prospective study with Swedish volunteers. Antimicrob Agents Chemother. 2010;54(9):3564-8. http://dx.doi.org/10.1128/AAC.00220-10

10. Weisenberg SA, Mediavilla JR, Chen L, Alexander EL, Rhee $\mathrm{KY}$, Kreiswirth BN, et al. Extended spectrum beta-lactamaseproducing Enterobacteriaceae in international travelers and non-travelers in New York City. PLoS One. 2012;7(9):e45141. http://dx.doi.org/10.1371/journal.pone.0045141

11. Leverstein-van Hall MA, Stuart JC, Voets GM, Versteeg D, Roelofsen E, Fluit AC. [Carbapenem-resistant Klebsiella pneumoniae following foreign travel]. Ned Tijdschr Geneeskd. 2010;154(37):A2013. Dutch.

12. Leverstein-Van Hall MA, Stuart JC, Voets GM, Versteeg D, Tersmette T, Fluit AC. Global spread of New Delhi metallo-betalactamase 1. Lancet Infect Dis. 2010;10(12):830-1. http://dx.doi.org/10.1016/S1473-3099(10)70277-2

13. Poirel L, Hombrouck-Alet C, Freneaux C, Bernabeu S, Nordmann P. Global spread of New Delhi metallo-beta-lactamase 1. Lancet Infect Dis. 2010;10(12):832.

http://dx.doi.org/10.1016/S1473-3099(10)70279-6

14. Walsh TR, Weeks J, Livermore DM, Toleman MA. Dissemination of NDM-1 positive bacteria in the New Delhi environment and its implications for human health: an environmental point prevalence study. Lancet Infect Dis. 2011;11(5):355-62. http://dx.doi.org/10.1016/S1473-3099(11)70059-7

15. Cloodt H. Air transport recovers in 2010. Luxembourg: Eurostat; 2012.

16. European Centre for Disease Prevention and Control (ECDC) Carbapenemase-producing bacteria in Europe: interim results from the European Survey on carbapenemase-producing Enterobacteriaceae (EuSCAPE) project. Stockholm: ECDC; 2013. 